InVisible Culture • Issue 33: After Douglas Crimp

\title{
After Douglas Crimp \\ Questionnaire Response: Tiffany E. Barber
}

\section{Tiffany E. Barber}

Published on: Jan 05, 2022

DOI: $10.47761 / 494 \mathrm{a} 02 \mathrm{f} 6.51746 \mathrm{ccd}$

License: Creative Commons Attribution 4.0 International License (CC-BY 4.0). 
HOMAGE, a score for Douglas*

Stand tall, feet together, feet apart

Smile slightly

Walk in a circle around yourself

Continuing walking, marking a square perimeter around the circle you just made

Stop whenever you feel like stopping

Stand tall, feet together, feet apart

Smooth your shirt, tuck it into your pants

Pause

Stand tall, feet together, feet apart

Let your hands and arms dangle at your sides

Bend your knees

Hinge forward slightly at the waist

Slowly hug your arms around the air in front you

Pause

Stand tall, feet together, feet apart

Smile slightly

Sit in the nearby mid-century armchair

Pause

Slowly cross your legs

Slowly bring your left hand to your forehead

Rest your elbow on the arm of the chair

Rest your head in your hand

Pause

Fold your hands together, rest them on your belly

Pause

Smile slightly

Stand tall

*repeat the score, increasing speed with every repetition, stop when you feel like stopping

Dr. Tiffany E. Barber is a scholar, curator, and critic of contemporary visual art, new media, and performance who shared with Douglas a love for dance. 


\section{Click here to return to the other questionnaire responses.}

